\title{
Cold fusion: pros and cons
}

\author{
Rainer W. Kühne \\ Lechstrasse 63, W-3300 Brunswick, Germany
}

Received 1 June 1990; revised manuscript received 2 April 1991; accepted for publication 2 April 1991

Communicated by J.P. Vigier

The observational data of several experiments which might have confirmed electrochemical fusion are discussed.

In order to verify whether electrochemical fusion exists three kinds of experiments have been performed, namely electrolysis of $\mathrm{D}_{2} \mathrm{O}$, deuteron implantation into metals and mechanical treatment of deuterated metals. Mass spectroscopic data and excesses of heat, gamma rays, helium, tritium, neutrons and protons have been interpreted to have originated from some fusion processes. Since most of the experiments to verify electrochemical fusion have failed and since several of the observational data of which their authors have claimed to have confirmed fusion are disputed or have been even withdrawn it is the aim of this paper to discuss possible conventional explanations for the excesses.

Excess heat has been observed by Fleischmann et al. [1-4], Bockris et al. [5,11], Pons [12,13], Koyama et al. [14], Landau et al. [6,15], Oyama et al. [16], Appleby et al. [7,17,24,33,34], Martin et al. $[8,35,36]$, Gozzi et al. [ $18,25,34]$, Wadsworth et al. [37], Huggins et al. [9,15,34,38,42], Wada and Nishizawa [43], Yamaguchi and Nishioka [44], MacKubre et al. [11], Scott et al. [96], Liebert and Liaw [45] and eventually by Charles et al. [46,47].

Five arguments can be mentioned to support the idea that the heat excesses have not originated by any fusion reactions. (i) The cells used by Appleby et al. have been tested some weeks after their experiment, however, no excesses of neutrons, helium or tritium large enough to explain the heat excess by pure $d-d$ fusion have been found [17,34]. (ii) Oyama et al. have detected excess heat and gamma rays, but no excesses of neutrons, tritium or helium [16]. (iii)
The cells used by Pons have produced a heat excess which has lasted for $2 \mathrm{~h}[12,13]$, but Salamon et al. were later able to show that during this period of time no excess gamma rays above limits of error have arisen [13]. (iv) Fleischmann et al. claim to have observed excess heat, however, they have withdrawn all their other claims $[4,48]$ (see below). (v) In all experiments where there has been observed excess heat the claimed production rates of neutrons, tritium, helium and gamma rays have been several orders of magnitude below the heat levels provided one assumes that the heat excess had originated by $d-d$ fusion (see refs. [5,16,18,25,34,44]).

These reasons have led several authors to support the idea that the heat excess might have been due to chemical reactions [49]. Recombination of deuterium and oxygen to $\mathrm{D}_{2} \mathrm{O}$ has been proposed [50,51], however, one has argued that the heat excess observed by Fleischmann et al. has been greater than expected if all the deuterium would have recombined with the oxygen $[52,53]$. Also one has assumed that the hydrogen, deuterium and tritium might have built molecules and ions [54]. Moreover combination of palladium and deuterium has been suggested [55]. However, it has to be noted that all these reactions do not yield much more energy than the recombination of $\mathrm{D}_{2}$ and $\mathrm{O}_{2}$. Other authors assume that changes in the heat transfer might have occurred [56]. Finally, where the experimenters have not stirred the electrolyte there could have arisen much less heat than assumed, provided that the temperature-sensing elements have been placed about 
above the cathodes $[19,42,49.50,56.57]$. In addition some other calorimetric errors have been suggested to be responsible for the claimed heat excess $[26,39,40,42,49,50]$. To be fair it has to be said that several experimenters who have observed some heat excess do not agree with the idea that calorimetric errors have occurred during their experiments (see e.g. ref. [45]).

Fleischmann et al. [1], Koyama et al. [14]. Oyama et al. [16]. Sanchez et al. [27]. Celani et al. [28.58], Scott et al. [96] and Aiello et al. [97] have claimed to have detected excess gamma rays. Decaying ${ }^{214} \mathrm{Bi}$ has been suggested to be a possible source [42]. Concerning the observations of Fleischmann et al. one was able to show that the observed peaks were inconsistent with the behaviour of the detector [49,59,60], therefore Fleischmann et al. have withdrawn their original claim $[4,48,53,61]$.

Helium has been observed by Fleischmann et al. [48] and possibly in the mass spectroscopic data by Kosyachkov et al. [62], Dickinson et al. [63], Wada and Nishizawa [43]. However, it was shown that Fleischmann et al. have not excluded the helium content of the air [49]. Moreover it was argued that helium remains in Pd for several years [64]. That is why Fleischmann et al. have withdrawn this claim. too $[4,15]$.

Fleischmann et al. [1], Wolf et al. [20,33.65,66]. Bockris et al. [67,68,98], Storms and Talcott [69]. Sanchez et al. [27], Sona et al. [29,99], Gozzi et al. [25], Celani et al. [28,58], Clayton et al. [45]. Aiello et al. [97], Iyengar et al., Yeager et al., Ramirez et al.. Scott et al., Schoessow et al. and Guruswamy et al. [66] have observed excess tritium. Also excess tritium might have been seen in the mass spectroscopic data of Kosyachkov et al. [62], Dickinson et al. [63], Wada and Nishizawa [43]. However, Wolf et al. have withdrawn their claim, because they have found some tritium contamination in their cells $[67,68]$. Since $\mathrm{D}_{2} \mathrm{O}$ contains tritium it has been argued that the observed tritium excesses might have been due to chemiluminescence [48-50]. Therefore Fleischmann et al. have withdrawn their claim $[4,15,48]$. Here, too, several authors doubt that impurities of tritium have been responsible for all the observations above (see e.g. refs. $[45,69]$ ).

Finally, one cannot exclude that ' $\mathrm{H}$ contamina- tion has led to the observation of protons in the mass spectroscopic experiments above.

Several teams have claimed to have detected excess neutrons. (i) Jones et al. stated to have observed a neutron excess [10,21.41.70-72], where the total rate was calculated to be over four standard deviations above background [71.73]. Some explanations have been suggested.

Fluctuations in the cosmic neutron background were suggested [74], however, it was shown that the absolute value of these fluctuations has not been more than 4\% [73]. This fact also contradicts the assumption [75] of the contribution of solar flare neutrons.

Cosmic ray muon catalysis was discussed. however, the muon flux is 200 times below the rate needed to explain the observed rate [76].

The idea of statistical and systematical biases was considered [77]. However, Jones et al. [73] were able to show that the idea of systematical biases does not fit the situation of the experiment. Furthermore. statistical biases alone cannot explain the observational data [77].

Various background runs have been performed: There have been used both unpowered cells and standard cells, but with $\mathrm{H}_{2} \mathrm{O}$ as the electrolyte instead of $\mathrm{D}_{2} \mathrm{O}$. By using various gamma ray and fission neutron sources one has tried to generate false signals. Finally, auxiliary equipment has been turned on and off. Since all these runs have given null results $[70,71]$ it is not likely that apparatus errors have been responsible for the observed excess.

(ii) Bertin et al. claimed to have detected a neutron excess in the Gran Sasso underground laboratory $[22,78]$. The total neutron rate can be estimated to be four standard deviations above the contemporary measured background. because in fig. 1 of ref. [78] there are given the values for one standard deviation for each run. (With the total rate the rates during the runs 17-20 of the four experiments are meant, because here the experimenters have expected to find excess neutrons.)

Since the background was measured contemporary by a second counter at a distance of $8 \mathrm{~m}$ from the cells and since each run was stopped after $4 \mathrm{~h}$ we can exclude fluctuations in the cosmic neutron background, solar flare neutrons, statistical and systematical biases to be possible explanations for the ob- 
servations. The noice within the used counters is only significant when neutrons and gamma rays are not well discriminated, therefore this process cannot explain the observed excess during the experiments 24. We have just seen that the flux of cosmic muons is too low to account for the neutron production rates [76]. To be complete I add a further argument against the idea of the contribution of muon catalysis. The Gran Sasso laboratory is about as well shielded as the Fréjus highway tunnel, for which an upper limit of the neutron background of $10 / \mathrm{h}$ was obtained by using cells containing deuterated Pd [79] - compare the data given in ref. [80] for the Gran Sasso laboratory.

(iii) Menlove et al. $[23,81]$ claim to have detected both neutron bursts and excesses of random neutrons. Much effort has been done to exclude sources of error or background.

Before the actual experiments the apparata have been tested for several weeks, the sample mass has been increased and the $\mathrm{CH}_{2}$ moderator has been removed. These experiments have shown that electronic drifts have been negligibly small and that the background baseline has not been significantly perturbed by the proximity of other objects in the room.

During the runs there have been used several counters simultaneously and dummy cells alternating in time to clearly identify apparatus errors and fluctuations in the neutron and cosmic ray backgrounds. It should be noticed that the experimenters have not found any significant variations in the neutron background before and during the experiments. Moreover they have been able to discriminate neutrons and cosmic rays by measuring the pulse shapes.

Very long runs have been performed which have been terminated at arbitrary times. This excludes the possibility of statistical and systematical biases.

Menlove et al. report that the excess of sample Ti1 was 10.3 standard deviations above background and that the bursts in the background have not yielded more than 30 neutrons within $10^{-4} \mathrm{~s}$, whereas those in the active samples have yielded up to 300 neutrons within $10^{-4} \mathrm{~s}$. Hence, statistical significance is clearly fulfilled.

(iv) Deryagin et al. have observed excess neutrons in 1986 [82] and in 1989 [83,84]. They claimed that the observed rates were six times above background, but that the detected efficiency was taken into account there [83]. However, from the given data one cannot exclude that the excess was not significantly above background by pure observation. Moreover it has not been written that contemporary background runs had been performed so that the observed excess might have been due to background fluctuations.

(v) A significant neutron excess was observed by Scaramuzzi et al. $[30,85,86]$. They explained the "quantized" structure of their counts by the saturation of their $\mathrm{BF}_{3}$ counter $[85,86]$. This is possible. But it was also pointed out that radioactive noise in the $\mathrm{BF}_{3}$ counter can lead to wrong results, hence care must be taken if these counters are used; e.g. several counters can be employed simultaneously $[50,87$, 88 ]. Scaramuzzi et al. have not stated in refs. [30,85, 86] that such care had been taken.

Yamaguchi and Nishioka [44] have observed three bursts. Each released about $10^{6}$ neutrons per second for about $2 \mathrm{~s}$ ( $10^{5}$ times above background). Simultaneously, they have observed an explosive release of gas from the samples and a biaxial bending of the samples due to uniform expansion of the surfaces of the Pd plates. They have found an increase of temperature of $50^{\circ} \mathrm{C}$ within the cells. Moreover the color of the gold deposited on one of the plate surfaces was lost. The authors attributed this observation to the alloying of the gold, hence temperatures above its alloying point of $1064^{\circ} \mathrm{C}$ should have arisen. This is interesting, because the experimenters have not performed electrolysis but mechanical treatment experiments to achieve fusion. Hence, calorimetric errors cannot be accounted for this observation.

But can one really exclude that the pressure has released the heat excess and that the high temperature has influenced the neutron counters, so that the neutron bursts have in reality been reactions of the counters on the (sudden) heat excess? However, I have to note that this is not a probable explanation, because such a reaction has never been observed in other mechanical treatment experiments, yet.

Mass spectroscopy was performed by Kosyachkov et al. [62]. During their run $b$ they observed peaks at mass numbers $M=1, M=2$ and $M=4$. After this they made run $\mathrm{d}$ by using the same electrodes. The $M=4$ peak was no longer visible, but $M=3$ appeared. They interpreted it to be due to ${ }^{3} \mathrm{He}^{+}$. How- 
ever. if the main contributor for the $M=3$ peak was ${ }^{3} \mathrm{He}$ which has originated by the reaction $\mathrm{d}(\mathrm{d}, \mathrm{n}){ }^{3} \mathrm{Hc}$ as they assumed, then at minimum $1 \%$ of all the deuterium within the metal foils had to fuse to create the strong $M=3$ peak. Even if we only assume a TiD system there had to be $6 \times 10^{21} \mathrm{~d} / \mathrm{cm}^{3}$. If only $1 \%$ of them have fused $3 \times 10^{19}$ fusions $/ \mathrm{cm}^{3}$ had 10 occur Since each fusion yields $3.3 \mathrm{McV}$ of free energy the total arising energy were $1 \times 10^{\prime} .1 \mathrm{~cm}^{3}$. Unform nately. the authors have not mentuoned the period of time for which run dhas lasted. Since run a has lasted for $20 \mathrm{~h}$ and run $\mathrm{h}$ for $6 \mathrm{~h}$ we will assume that run $\mathrm{d}$ has lasted for $1000 \mathrm{~h}$. In this case the arisen trec powe were $3 \mathrm{~W} \mathrm{~cm}$. Even this very minmum value would probably have melted the $T$ i fonls icf. the ix periments of Fleischmann at al. [89]. Gozzi et at. [18,25.34]. Yamaguchi and Nishioka [44]. however. they have not written that this had occurred.

Since the experimenters sontradicted the ldea that the $M=3$ peak had been due to $\mathrm{HD}^{+}$one has $10 \mathrm{con}-$ sider experimental or apparatus errors as possible explanations. As is writuen in ref $[62]$ the $1 /=6$ peak might have been duc to tritium impurity, $D_{:}^{+}$or $\mathrm{H}_{2} \mathrm{D}_{2}^{+}$

Let us labulize what might have been detected by the various expermentors

(1) Jones at al. 17071$]$ have reponted thal onit those runs have veided excess ncutrons whete thich has been used deuicrium mstead of normathydregen

(2) Jones el a! $[70.21]$, Bertun et at. $17 x$ and Wolf et at $\{20\}$ have written that pulse shape data have show that the execss nutrons havecrergies of about $2.5 \mathrm{MeV}$ And Tanizuch a a! : 90 ] have ported that the exeess protons have energies of alout $3 \mathrm{MeV}$.

(3) Meniove er a! [23.81] claim to have observed bursts of $10-300$ neutrons withen $10^{-4} \mathrm{~s}$.

(4) Bursts of 19$)^{4} .16$ ncutrons within is $10.30 \mathrm{~mm}$ mighi have been detected by Deryagin el al. $[82-8+1$. Ceiani et ai [28.58], GozZl et al. [18.2534], Greber et al. [3]]. Yamaguch and Nishoka [44]

(5) Simulaneously to these bursts there might have been deleeted excess heal [44] and excesses of charged particles and gamma rays $[28.581$.

(6) It has been reported that the various excesses have dissappeared after $3 \mathrm{~h}$ (Bertin et al. [78\}) \% 8 $h$ (Jones et ai. $[70.71]$ and Emmoth et al $\{32\}), 33$ h (Bockris et al. [11]) and $500 \mathrm{~h}$ (Sanchez et al [27]), respectively.

(7) Sanchez el al. [27], Gozzi et al. [18.25,34] and Sona et al. [29] have reported that the ratio of excess tritium to neutrons has been several orders of magnitude above unity.

(8) Jones et al. [70.71]. Bertinet al. [78]. Menlove et al. [23.81]. Wiesener et al. [48], Aiello et al [97] and Wolf el al. [20] have written that excess neutrons of rates as small as about $0.1 / \mathrm{s}$ have arisen

(9) There could have arisen much more excess hear than can be explained by the detected fusion product rates in the experiments of Bockris et al. 151 Grama et al. 1101 . Gozz ot al. [18.25.34] Yamaguchi and Nishioka [44]. See also the experiments of Fleischmann et al. $[1,4]$. Pons [12.13] and Appleby ut al. $[17.34]$

(10) Even several of the experimenters who hate contirmed the production of some excesses above have not been able to reproduce their results in all their cells (Meniove at al. [23.81]. Bockris et al [5.11]. Celani er al. [28.58], Greberet al. [31] Yamaguchi and Nishiokat $[44]$

Several authors who have confidence in the physcal ongin of the observations above have discussed micro hot fusion as a possible explanation $[6,76,8$ ?$84.91-941$ According to this model deuterons can acomulate winin bubbles af sices of up to $10 \mathrm{\mu m}$ in $P d$ and $T$. Varrations of pressure, temperature applied current and voliage may lead to cracks and simultancously to electric fields of $10 \mathrm{~V} / \mathrm{cm}$ within the erdeks. This means that each deuteron within the: cracks can obtain an energy of up $1010 \mathrm{keV}$. This merease of energy will increase the $\mathrm{d}-\mathrm{d}$ fusion probability Hence $2.5 \mathrm{MeV}$ neutrons and $3.0 \mathrm{Mi} \mathrm{V}$ protons wili be created. As the electrical fields disappear rapidy it is understandable that the fusion reactions car only occur within small periods of time (bursis!) Moreover Segre et al have shown that there is a orrelation between the number of fusion reactions and the maximum energy which deuterons can obiain For $10-100 \mathrm{ke} / \mathrm{ker}$ detiteron there should occur $10^{4}$ 10 fusion reactions per em "of metal [91]. If we assume that each deuteron obtains the energy $10 \mathrm{keV}$ we will expect. because of the fusion probability catculated in ref, 1911 . that only one of. say, $10^{\circ}$ deuterons will fuse with another one. The others will quickly lose their energies by collisions. Hence. the 
energy output will be about $10^{10}$ times the one expected by pure $\mathrm{d}-\mathrm{d}$ fusion reactions. Also this model is able to explain why this process has not been reproducible, yet. Segre et al. [91] have listed several conditions which have to be satisfied to allow bubble formation.

\section{References}

[1] M. Fleischmann, B.S. Pons and M. Hawkins, J. Electroanal. Chem. 261 (1989) 301; 263 (1989) 187 (E).

[2] B.S. Pons and M. Fleischmann, Fusion Technol. 17 (1990) 669.

[3] B.S. Pons, report ACS-Meeting, Dallas, 19 April 1989.

[4] M. Fleischmann and B.S. Pons, report ECS-Meeting, Los Angeles, 8 May 1989.

[5] J. O'M. Bockris, report ECS-Meeting, Los Angeles, 8 May 1989.

[6] U. Landau, report ECS-Meeting, Los Angeles, 8 May 1989.

[7] A.J. Appleby, report ECS-Meeting, Los Angeles, 8 May 1989

[8] C. Martin, report ECS-Meeting, Los Angeles, 8 May 1989.

[9] R.A. Huggins, report ECS-Meeting, Los Angeles, 8 May 1989.

[10] S.E. Jones, report ECS-Meeting, Los Angeles, 8 May 1989.

[11] R.C. Kainthla, O. Velev, L. Kaba, G.H. Lin, N.J.C. Packham, M. Szklarczyk, J. Wass and J. O'M. Bockris, Electrochim. Acta 34 (1989) 1315.

[12] B.S. Pons, report NSF/EPRI-Meeting, Washington, DC, 1618 October 1989.

[13] M.H. Salamon, M.E. Wrenn, H.E. Bergeson, K.C. Crawford, W.H. Delenay, C.L. Henderson, Y.Q. Li, J.A. Rusho, G.M. Sandquist and S.M. Seltzer, Nature 344 (1990) 401.

[14] Nature 338 (1989) 447, unsigned.

[15] D. Lindley, Nature 339 (1989) 84.

[16] D. Swinbanks, Nature 339 (1989) 167.

[17] A.J. Appleby and S. Srinivasan, report LANL-Meeting, Santa Fe, 23-25 May 1989.

[18] D. Gozzi, report LANL-Meeting, Santa Fe, 23-25 May 1989.

[19] N.S. Lewis, report LANL-Meeting, Santa Fe, 23-25 May 1989.

[20] K.L. Wolf, report LANL-Meeting, Santa Fe, 23-25 May 1989.

[21] S.E. Jones, report LANL-Meeting, Santa Fe, 23-25 May 1989.

[22] A. Bertin, report LANL-Meeting, Santa Fe, 23-25 May 1989.

[23] H.O. Menlove, report LANL-Meeting, Santa Fe, 23-25 May 1989.

[24] A.J. Appleby, Y.J. Kim, O.J. Murphy and S. Srinivasan, report Il Nuovo Cimento Conf., Varenna, 15-6 September 1989.

[25] D. Gozzi, P.L. Cignini, L. Petrucci, M. Tomellini, G. De Maria, S. Frullani, F. Garibaldi, F. Ghio and M. Jodice, report Il Nuovo Cimento Conf., Varenna, 15-16 September 1989.
[26] D.E. Williams, D.J.S. Findlay, D.H. Craston, M.R. Sené, M. Bailey S. Croft, B.W. Hooton, C.P. Jones, A.R.J. Kucernak, J.A. Mason and R.I. Taylor, report Il Nuovo Cimento Conf., Varenna, 15-16 September 1989.

[27] C. Sanchez, J. Sevilla, B. Escarpizo, F. Fernandez and J. Canizares, report Il Nuovo Cimento Conf., Varenna, 15-16 September 1989.

[28] F. Celani, M. De Felici, F.L. Fabbri, L. Liberatori, A. Saggese, A. Spallone, V. Di Stefano, P. Marini, S. Pace, S. Bianco and L. Donati, report Il Nuovo Cimento Conf., Varenna, 15-16 September 1989.

[29] P.G. Sona, F. Parmigiani, F. Barberis, A. Battaglia, R. Berti, G. Buzzanca, A. Capelli, D. Capra and M. Ferrari, report Il Nuovo Cimento Conf., Varenna, 15-16 September 1989.

[30] A. De Ninno, A. Frattolillo and F. Scaramuzzi, report Il Nuovo Cimento Conf., Varenna, 15-16 September 1989.

[31] T. Greber, A. Fischer, C. Rheme, S. Drissi, J. Osterwalder, J. Kern and L. Schlapbach, report II Nuovo Cimento Conf., Varenna, 15-16 September 1989.

[32] B. Emmoth, I. Gudowska, W. Gudowski and M. Jandel, Il Nuovo Cimento Conf., Varenna, 15-16 September 1989.

[33] D. Lindley, Nature 339 (1989) 325.

[34] R. Pool, Science 244 (1989) 1039.

[35] R. Pool, Science 244 (1989) 143.

[36] R. Pool, Science 244 (1989) 774.

[37] R. Pool, Science 245 ( 1989 ) 256.

[38] R.A. Huggins, report APS-Meeting, Baltimore, 1 May 1989. [39] N.S. Lewis, report APS-Meeting, Baltimore, 1 May 1989.

[40] W. Meyerhof, report APS-Meeting, Baltimore, 1 May 1989

[41] S.E. Jones, report APS-Meeting, Baltimore, 1 May 1989.

[42] D. Lindley, Nature 339 (1989) 4.

[43] N. Wada and K. Nishizawa, Japan. J. Appl. Phys. 28 (1989) L2017.

[44] E. Yamaguchi and T. Nishioka, Japan. J. Appl. Phys. 29 (1990) L666.

[45] J. O'M. Bockris, New Sci. 129, no. 1752 (1991) 50.

[46] R.D. Armstrong, E.A. Charles, I. Fells, L. Molyneux and M. Todd, Electrochim. Acta 34 (1989) 1319.

[47] R.D. Armstrong, E.A. Charles, I. Fells, L. Molyneux and M Todd, J. Electroanal. Chem. 272 (1989) 293.

[48] J.W. Schultze, U. König, A. Hochfeld, C. van Calker and W. Kies, Electrochim. Acta 34 (1989) 1289.

[49] N.S. Lewis, C.A. Barnes, M.J. Heben, A. Kumar, S.R. Lunt, G.E. McManis, G.M. Miskelly, R.M. Penner, M.J. Sailor, P.G. Santagelo, G.A. Shreve, B.J. Tufts, M.G. Youngquist, R.W. Kavanagh, S.E. Kellogg, R.B. Vogelaar, T.R. Wang, R. Kondrat and R. New, Nature 340 (1989) 525.

[50] D.E. Williams, D.J.S. Findlay, D.H. Craston, M.R. Sené M. Bailey, S. Croft, B.W. Hooton, C.P. Jones, A.R.J. Kucernak, J.A. Mason and R.I. Taylor, Nature 342 (1989) 375.

[51] M. Marinelli, G. Morpurgo, S. Vitale and G.L. Olcese, Nuovo Cimento A 102 (1989) 959.

[52] C. Walling and J. Simons, J. Phys. Chem. 93 (1989) 4693.

[53] B.G. Levi, Phys. Today (June 1989) 17.

[54] M.E. Bridge, D.R. Lloyd and J.M.D. Coey, Nature 340 (1989) 105. 
[55] L. Pauling. Nature 339 ( 1989 ) 105.

[56] G.M. Miskelly, M.J. Heben. A. Kumar. R.M. Penner. M.I. Sailor and N.S. Lewis, Science 246 (1989) 793.

[57] R.L. Garwin. Nature 338 (1989) 616

[58] F. Celani, A. Spallone, S. Pace. B. Polichetti. A. Saggest. L. Liberatori. V. Di Stefano and P. Marini. Fusion Technol. $17(1990) 718$

[59] R.D. Petrasso, X. Chen. K.W. Wenzel. R.R. Parker. ('.K. Li and C. Fiore. Nature 339(1989) 183, 264 (E).

[60] R.D. Petrasso, X. Chen, K.W. Wenzel. R.R. Parker. C.K. Li and C. Fiore. Nature 339 (1989) 667

[6 1 ] M. Fleischmann, B.S. Pons. M. Hawkins and R.J. Hoffman. Nature 339 ( 1989 ) 667

[62] A.A. Kosyachkov, V.S. Triletskii, V.T. Cherepin and S.M Chichkan', JETP Lett. 49 (1989) 744.

[63] J.T. Dickinson, L.C. Jensen, S.C. Langford, R.R. Ryan and E. Garcia, J. Mater. Res. 5 (1990) 109

[64] G.C. Abell, L.K. Matson. R.H. Steinmeyer, R.C. Bowman and B.M. Oliver, Phys. Rev. B 41 (1990) 1220.

[65] N.J.C. Packham, K.L. Wolf. M.E. McLain and J. OM. Bockris. J. Electroanal. Chem. 270 (1989) 451.

[66] G. Taubes, Science $248(1990) 1299$.

167] R. Pool, Science 248 (1990) 1301.

[68] D. Lindley, Nature 345 (1990) 561.

[69] E. Storms and C. Talcott. Fusion Technol. 17 (1990) 680.

[70] S.E. Jones, E.P. Palmer, J.B. Czirr. D.L. Decker, G.L. Jensen. J.M. Thorne, S.F. Taylor and J. Rafelski. Nature 338 (1989) 737

[71] S.E. Jones, E.P. Palmer, J.B. Czirr, D. L. Decker, G.L. Jensen. I.M. Thorne, S.F. Taylor and J. Rafelski. J. Fusion Energs Y $(1990) 199$

[72] S.E. Jones and J.B. Czirr, report Ettore Majorana Centre Conf. Erice, 12 April 1989.

[73] S.E. Jones, D.L. Decker and H.D. Tolley, Nature 343 (1990) 703.

[74] J.M. Carpenter, Nature 338 (1989) 711.

[75] E.M. Altas, K.W. Chambers, W. Dueck, R. Dutton and A.K. Mcllwain. Nature 344 (1990) 390

[76] J.S. Cohen and J.D. Davies, Nature 338 (1989) 705.

[77] S. Feedman and D. Krakauer, Nature 343 (1990) 703.

[78] A. Bertin, M. Bruschi, M. Capponi, S. De Castro, U! Marconi, C. Moroni, M. Piccinini. N. Semprini-Cesari. A. Trombini. A. Vitale, A. Zoccoli. S.E. Jones, J.B. Czirr, G.1 Jensen and E.P. Palmer, Nuovo Cimento 101A (1989) 997.

[79] F. Botter. J. Bouchez, J. Collot, E. Kajfasz, B. Lefievre, F. Lesquoy, A. Stutz, S. Tistchenko and S. Zvlberajch. Phis. Lett. B 232 (1989) 536
[80] P. Belli, R. Bernabei. S. D Angelo. M.P. De Pascale, 1 Paoluzi, R. Santonico, N. Taborgna. N. lucci and $;$ Villoresi. Nuovo Cimento I01A (1989) 959 .

[81] H.O. Menlove. M.M. Fowler. F. Garcia M.C. Miller. M.A Paciotti, R.R. Ryan and S.E. Jones. I. Fusion Energy 9 (1990) 495

[82] V.A. Klyues. A.G. I.ipson, Yu.P. Toporow and B.Y Deryagin. Sov. Phys. Tech. Letl. 12 (1986) 551

[83] A.G. Lipson, D.M. Sakor, V. A. Klyuev, B.V. Deryagin and Yu.P. Toporov, JETP Lett. 44 (1989) 075

[84] B.V. Deryagin. A.G. Lipson. V.A. Klyuev. D. M. Sakov and Yu.P. Toporov. Nature $341(1989) 442$

|85|A. De Ninno, A. Frattolillo, (;. Lollobattista, L. Martinis M. Martone. L. Mori. S. Podda and F. Scaramuzi. Nuovo Cimento 101A (1989)841.

[86] A. De Ninno. A. Frattolillo, G. Lollobatista, L. Martinis M. Martonc, L. Mori, S. Podda and F. Scaramuzzi Europhys. Lett. 9 (1989) 221

[87] D. Alber. O. Boebel. C. Schwarz. H. Duwe, D. Hilscher. H Honeyer, I. Jahnke and B. Spellmeyer. Z. Phys. 1333 (1989) 319.

[88] G.M. McCracken, M. Bailey S. (roft, D.J.S. Findlay \& Gibson. R.P. Govier O.N. Jarvis. H.I Milton. B.A. Powell G. Sadler M.R. Sene. D.R. Sweetman. P. van Belle and H.H.H. Watson, J. Phys. D) $23(1990) 469$

[89] R. Pool, Science 244 (1989) ??

[90] R. Taniguchi. T. Yamamoto and S. Iric, Japan. J. Appl. Phy $28(1989) 12021$

[91] S.E. Segre, S. Atreni, S. Briguglio and F. Romanelli Europhys Le11. $11(1990) 201$

192| R. Seitz. Nature $339(1489) 185$

[93] V.I. Goldanskii and F.I. Dalidchik. Nature 342 (1984) 231

194 ] J.S. Cohen and J.D. Davies. Nature 342 (1989) 488 .

[95] J.C. Jackson. Nature $339(1989) 345$.

196] C.D. Scott. J.E. Mrochck. T.C Scon, (i.E. Michacls, Newan and M. Petek. Fusion Technol. $18(1990)$ 103.

[97] S. Aiello. E. de Filippo. G. Lanzano. S. Lo Nigro and 1 Pagano. Fusion Technol. $18(1990) 115$

[98] G.H. Lin. R.C Kainthla N.I.C. Packham, O. Velev and I OM. Bockris. Int. J. Hydrog. Energy 15 (1990) 537

[49] P.G. Sona. F. Parmigiani. F. Barberis. A. Battaglia. R. Berti (i. Buzzanca. A. Capelli. D. Capra and M. Ferrari, Fusion Technol. $17(1990) 713$ 